Int. J. Electrochem. Sci., 13 (2018) 8481 - 8495

\title{
Enhanced Electrocatalytic Activity of Graphene-Gold Nanoparticles as a Superoxide Anion Biosensor Based on Immobilized Hemin
}

\author{
Beibei Wang ${ }^{1}$, Kai Kang ${ }^{1}$, Xueping $\mathrm{Ji}^{1,2, *}$, Yuheng Liu ${ }^{1}$, Xianrui $\mathrm{Li}^{1}$, Na Wang ${ }^{1}$, Jujie Ren ${ }^{3, *}$ \\ ${ }^{1}$ School of Pharmacy, Hebei Medical University, Shijiazhuang 050017, PR China \\ ${ }^{2}$ Hebei Key Laboratory of Forensic Medicine, Shijiazhuang 050017, PR China \\ ${ }^{3}$ Department of Chemistry, School of Sciences, Hebei University of Science and Technology, \\ Shijiazhuang 050018, PR China \\ *E-mail: xuepingji@126.com, xpji03@yahoo.com.cn, jujieren@126.com
}

doi: $10.20964 / 2018.09 .12$

Received: 4 April 2018 / Accepted: 25 May 2018 / Published: 5 August 2018

Inspired by the high electrocatalytic activity of electrochemically reduced graphene oxide-Au nanoparticles (ERGO-AuNPs) nanohybrid and their strong adsorption capacity for immobilizing biomolecules, we developed an ultrasensitive superoxide anion $\left(\mathrm{O}_{2}{ }^{--}\right)$electrochemical biosensor based on hemin immobilized on ERGO-AuNPs nanohybrid modified glass carbon electrode (GCE). The electrochemical properties of immobilized hemin were investigated. A considerably higher surface concentration $\left(\Gamma^{*}\right)$ of the immobilized hemin was measured on the order of $1.02 \times 10^{-7} \mathrm{~mol} \mathrm{~cm}^{-2}$. The results indicated that the ERGO-AuNPs nanohybrid enhanced the electrocatalytic activity of hemin for $\mathrm{O}_{2}{ }^{--}$detection due to the synergy generated by ERGO and AuNPs. The resulting biosensor exhibited an excellent amperometric response toward $\mathrm{O}_{2}{ }^{--}$, at linear ranges of $3.28 \times 10^{-5}$ to $3.28 \times 10^{-4} \mathrm{M}$ with sensitivities of $186 \mathrm{nA} \mu \mathrm{M}^{-1} \mathrm{~cm}^{-2}$ and $124 \mathrm{nA} \mu \mathrm{M}^{-1} \mathrm{~cm}^{-2}$ at $0.5 \mathrm{~V}$ and $-0.1 \mathrm{~V}$, separately. The apparent Michaelis-Menten constant $\left(K_{\mathrm{m}}\right)$ was estimated to be $0.51 \mathrm{mM}$ and $0.48 \mathrm{mM}$ at $0.5 \mathrm{~V}$ and $-0.1 \mathrm{~V}$, respectively, which indicated a clearly stronger interaction of hemin with $\mathrm{O}_{2}{ }^{\circ-}$. The results indicated that the biosensor have strong potential for analysis of biological molecules.

Keywords: Superoxide anion, Electrochemical reduced graphene oxide, Au nanoparticles, Nanohybrid, Biosensor

\section{$\underline{\text { FULL TEXT }}$}


(C) 2018 The Authors. Published by ESG (www.electrochemsci.org). This article is an open access article distributed under the terms and conditions of the Creative Commons Attribution license (http://creativecommons.org/licenses/by/4.0/). 